\title{
Electric Heating and Cooking
}

\section{Some Suggestions as to Possible Future Development}

\section{By P. Wilcox Gumaer}

DRING the past century there has been a great Each improvement has resulted in less waste of the heat energy and in a greater absorption of it by the food. Each step from the open fireplace to the coal range, to the gas stove, and finally to the electric range has been marked by the use of more expensive fuel, greater heat efficiency, better control of the heat and more satisfactory food.

Electric cooking at the present time has reached a state of development similar to that of the electric light about 1890. While still a luxury in some communities, it is being rapidly introduced at rates which allow direct competition with gas. At three cents pe kilowatt hour the housewife who owns a modern electric range can cook as economically as a person who uses a gas range and pays a dollar per 1,000 cubic feet for the gas.

From the crude, unreliable, and inefficient electric cooking apparatus first offered to the public, there have been developed the attractive, economical and durable devices of to-day. Many difficult problems of design have been solved, the greatest of which has been the electrical insulation at the high temperatures. Mica, the best insulator available at the highest temperatures met with in the other electrical apparatus, becomes a source of frequent breakdowns when used at the extreme temperatures necessary in heating devices. The dehydration temperature of the mica, $800 \mathrm{deg}$. C., is the limiting factor to the operating temperature of the unit when that insulation is used. The rate of flow of the heat into the cooking utensil from the material in which it is generated by the electric current is proportional to the temperature of that material. Hence, apparatus in which mica is used adjacent to the heating material must be very slow in operation when compared with gas or coal.

Porcelain has been used by some manufacturers as an insulator and support for the heating unit. Coils of michrome wire are stretched in the grooves of a porcelain support. This heating unit has been popular with persons accustomed to the use of a gas flame, as the coils of wire become red hot and give the appearance of intense heat. In order to insulate the live coils from the cooking utensil about an eighth of an inch of clearance is left between the coils and the top of the porcelain support upon which the utènsil rests. Since air is a poor thermal conductor the heat is transmitted to the cooking utensil by radiation and convection rather than by conduction. For heating large quantities of water or food and for continuous operation, these units are not as efficient as other types. For heating small quantities, however, they are more rapid in operation, due to the small mass. and low thermal capacity of the unit.

Recently an entirely new heating unit has been developed for electric heating devices. The high resistance wire through which the electric current flows is enclosed in a steel sheath, and insulated therefrom by a material which will. withstand excessively high temperatures without deterioration. The core wire and the powdered insulation are inserted in the sheath when the three are large in diameter. They are then rolled and swaged to the proper size. By an ingenious arrangment, the ends or terminals of the unit are left large in diameter, as shown in Fig. 1. This facilitates the attachment of terminal connections and permits the terminal to operate at a low temperature.

The outside metal sheath protects the core wire from oxidation when operated at high temperatures, as air cannot penetrate through the sheath and as the core wire is large in cross-section and comparatively cool where it is exposed to the air. If the operating temperature of the sheath is to exceed $400 \mathrm{deg}$. C., the unit is calorized. This protects the steel from oxidation so that it may be operated at very high temperatures for several thousand hours.

This type of heating unit lends itself readily to the onstruction of a hotplate or stove, which is practically ideal. The sheathed wire is arranged in a flat coil and molten iron is cast around it. The result is a beating unit, which is as rugged and durable as an old-fashioned stove lid. 2ig. 2 shows a cast iron hotplate without its thermat insulation underneath. Good thermal contact is obtained from the resistance wire thermal contact is obtained from the resistance wire
to the sheath, to the cast iron and by means of the smooth flat surface to the dish of food. This low thermal resistance path for the heat and the heat insulating pad beneath the unit secure an especially high efficiency. The smooth top and flat surface of the heating unit are ideal for cleanliness as there are no grooves or crevices in which dirt or spilled food can collect. Oven and broiler units are constructed as shown in Fig. 3. As the sheath does not have to be insulated from the oven the most simple of meta

On the Pacific coast where cheap water power is available and where coal is expensive, electric heating of the dwellings and offices is economically practical Rates as low as half a cent per kilowatt-hour have been offered by power companies for continuous loads, such as water heating and house heating. An interconnected water heater and electric range have become very popular in that section. The range and the water heater are connected to the same switch so that when the

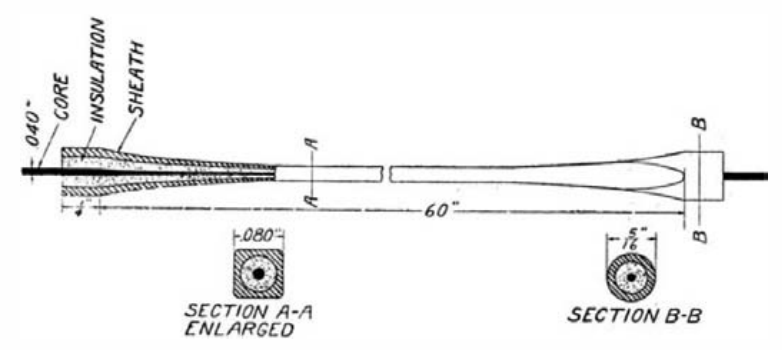

Fig. 1.-Sheathed wire

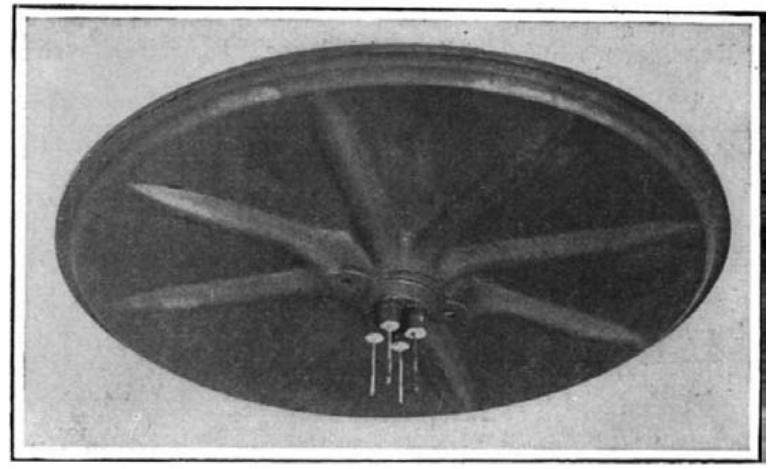

Fig. 2.-Sheathed-wire hot plate

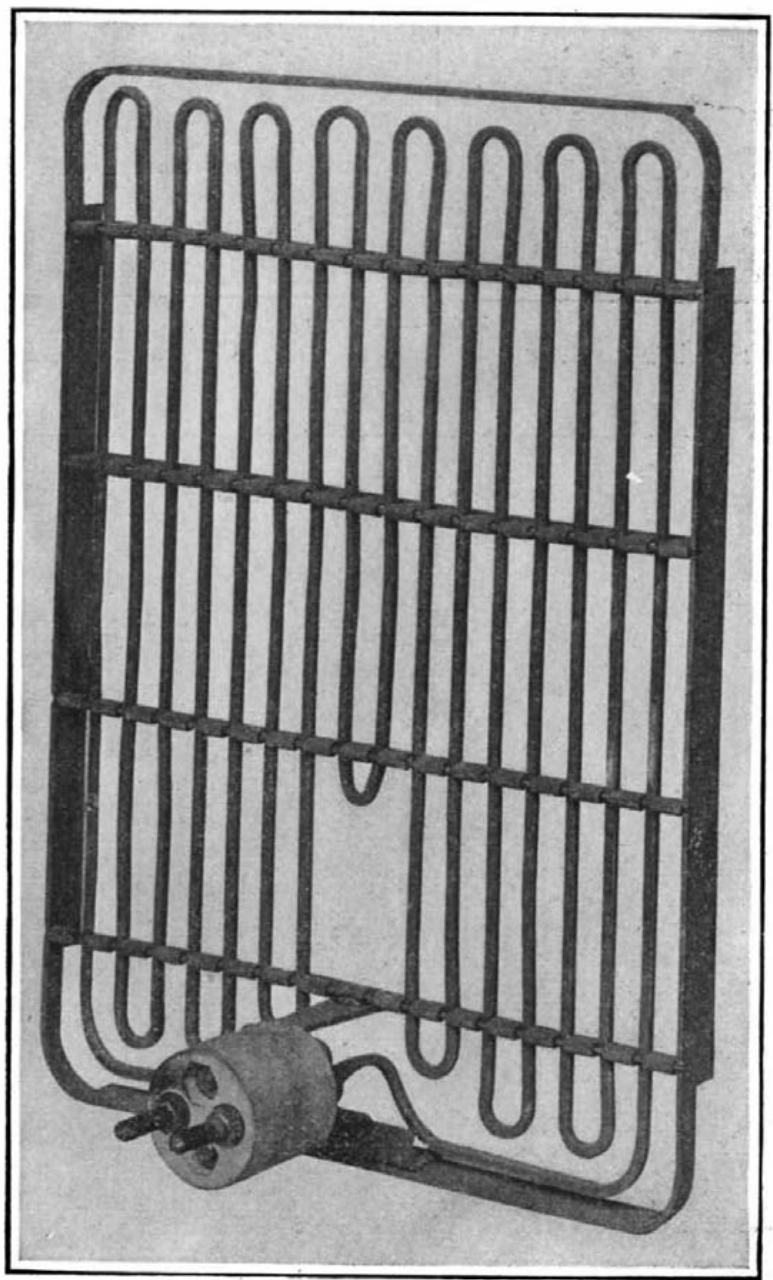

Fig. 3.-Open-coil sheathed-wire heating urit

range is not in use the power is used to heat water for household purposes. This arrangement results in a very high load factor.

The heating of residences by electricity in the east where cheap coal is available is very far in the future In a pound of coal there are approximately thirtee to fourteen thousand British thermal units and in kilowatt-hour 3,415 British thermal units. Hence, a pound of coal contains as much energy as four kilowatt-hours. Assuming an efficiency of 25 per cent for a coal furnace and 100 per cent for an electrical radia coal furnace and 100 per cent for an electrical radi-
ator, a pound of coal will furnish as much heat as one kilowatt-hour. Neglecting cost of attendance and maintenance, direct competition of electricity with coal for residence heating will require a rate per kilowatt-hour equal approximately to the cost of a pound of coal.

Water heating in quantities large enough to utilize separate coal or gas water heater is in the same class with house heating when compared with electricity. For direct competition similar low rates would have to obtain for the electrical energy except where attendance is a large factor.

The reader will probably raise the question as to why electricity is able to compete with gas or coal for cooking purposes when the cost for a given amount of energy at the meter or in the coal bin is so much greater for the electrical method. The answer is that cooking food is not a question alone of heat units. The steam boiler methods of obtaining efficiency do not give a correct indication of the cost of cooking operations. Briefly stated, the objects of cooking food are: (1) to render it more digestible so that the digestive organs can more easily digest and absorb the nutrient parts (2) to make the food more appetizing by improving it appearance and by developing in it new flavors; (3) to sterilize it so that it will keep longer. The relative importance of each purpose depends upon the article of food which is to be cooked. For example, in the cooking of animal foods; the improvement of the flavor and the appearance is the most important. Th cooking of these foods which are rich in protein actually decreases their digestibility. This is true at least of the chemical processes of digestion, but the increased attractiveness of well cooked meat may render it indirectly more digestible by causing a great flow of the digestive juices. The effect of heat on the protein of foods is to coagulate it. This change occurs at the com paratively low temperature of $\mathbf{7 5} \mathrm{deg}$. Cent. If the temperature is increased much above this point, the protein tends to shrink and harden, and the digestibility of the food is greatly lessened thereby.

It is not desirable, necessarily, as in heating water to put as many as possible of the heat units of the fuel into the food. In fact, the method of cooking in which the greatest number of the heat units of the fuel are absorbed by the food does not always give the most satisfactorily cooked food.

The present status of the science of cookery is due in a large degree, to the lack of adequate means of controlling the temperature of the food. When using the ordinary wood or coal cooking range the degree of heat is controlled chiefly by dealing with the food itseif rather than by regulating the heat at the point of combustion. The amount of draft necessary to promote the combustion of the fuel causes too great a degree of heat in the oven or on the stove to enable the cook to deal with the food in the proper way except by constantly watching it, stirring it, and changing the position of the vessel on the stove or in the oven. With the advent of electric ovens a revolution in the methods of cooking has become possible. Automatic electric oven will probably be developed in which the temperature will be accurately controlled and the necessity of constant vigilance will be removed. Some kinds of food will even be prepared in advance, placed in the oven, and without any further attention on the part of the housewife the current will automatically be turned on at a predetermined time. The temperature of the ove will increase to the desired value and there remain constant until the food is properly cooked.

With this method perfected the advantages of electric cooking over the other methods will be great and in many cases the cost will not be excessive. To the possibility of obtaining uniformly well cooked food should be added the saving to the housewife in time and worry and the absence from the kitchen of excessive heat The present-day problem in electric cooking is to determine the methods of cooking that will yield the most in nutrition and flavor, and to formulate definite rules or directions so that a particular article of food can be cooked in the best possible manner by persons of ordinary skill. The engineer's problem is then to design practical cooking devices in which the temperature can be accurately regulated with a minimum of attention on the part of the housewife

The increased popularity of the fireless cooker indicates that people are learning that food can be cooked at temperatures lower than the boiling point of water. The particular temperature of $100 \mathrm{deg}$. Cent. has long been the one used for cooking cereals, vegetables an meats, because it is the easiest temperature to maintain at a constant value and not necessarily because it give the best possible results. The fact that several hours are required for the cooking is not a disadvantage when (Concluded on page 508) 


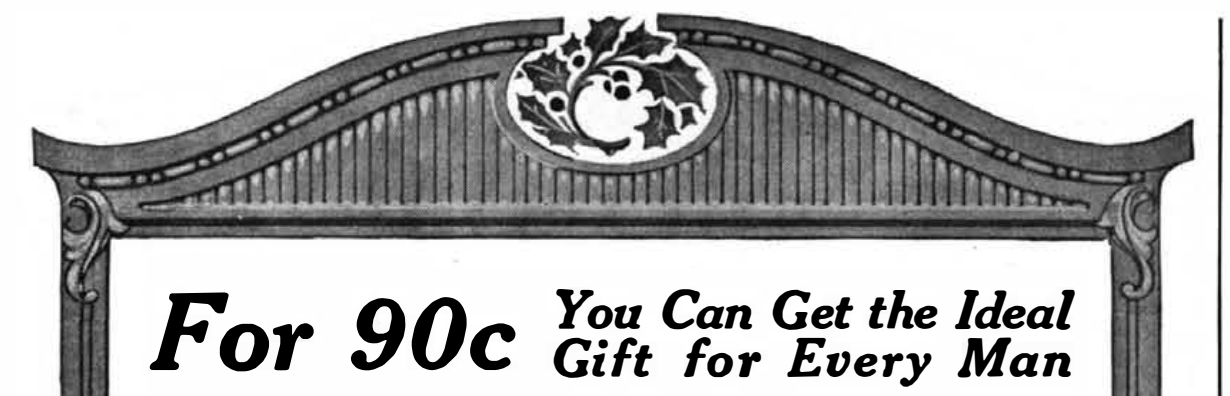

A crystal glass humidor jar containing one pound of Tuxedo, the mildest, most fragrant tobacco.

The spirit of Christmas is the spirit of Cheerfulness and Good Will to Men-and that is the Tuxedo spirit.

Tuxedo is the mildest, pleasantest pipe tobacco in the world - made absolutely non-biting and delightfully mellow by the original "Tuxedo Process" that has never been successfully imitated.

Tuxedo is sold everywhere-but if by any chance you cannot obtain the Christmas Jar of Tuxedo at your store, send us your dealer's name and $90 \mathrm{c}$, and we will send a jar to you or to any address in the United States you desire, all charges paid.

Last Christmas the demand for Tuxedo humidor jars was so great that

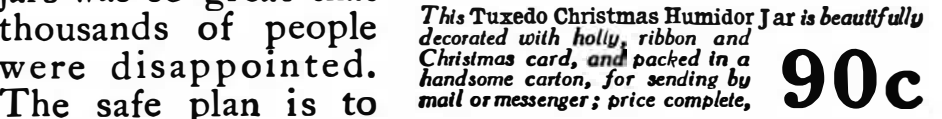
The safe plan is to
place your orderwith your dealer now. SOLD IN MANY

CONVENIENT SIZES

In Glass Humidors, - $50 \mathrm{c}$ and 900
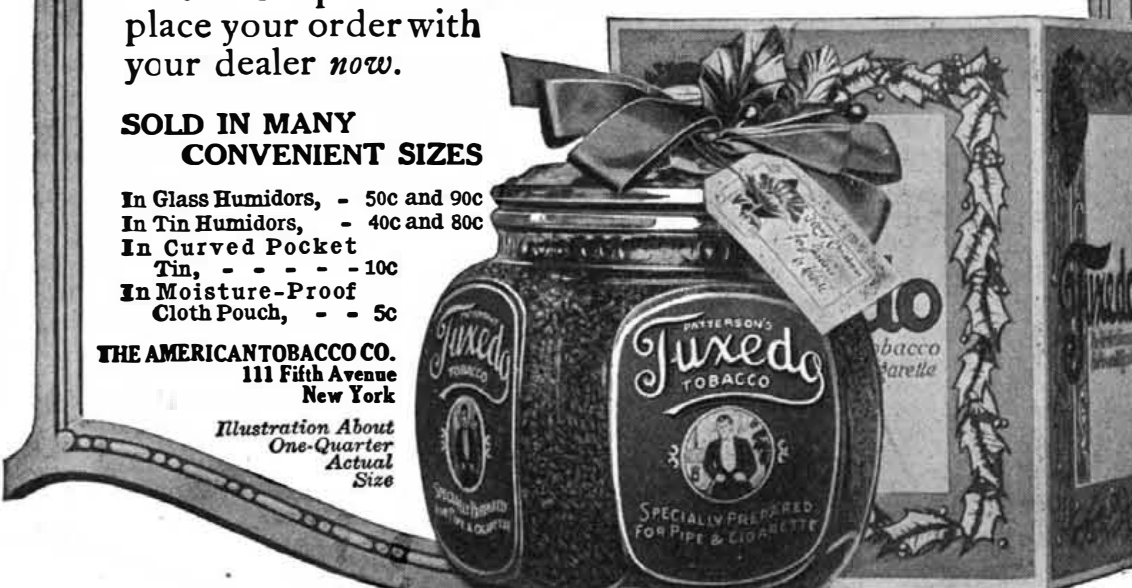

\section{For 90c You Can Get the Ideal}

heavily intrenched hills, by a group of that give the city its defensive strength. These hills have been lined with Austrian artillery which up to the present writing has held the Italians at bay. Just north of Gorizia the mountain country come down rapidly to the plain on which the city is situated. The Isonzo here comes through a deep gorge-like ravine into the open country, and breaking away slightly to the west, follows along the western foot of a large table land, the Plateau of Corso. Directly west of Gorizia, on the other side of the river, are found the mountains, on one of the spurs of which is the town of Podgora, below which run both the railroad and the highway into Gorizia. Because of the fact that this highway and railroad cross the river at the foot of the elevation on which Gorizia is situated, and because also of its excellent position for observation and artillery Podgora would seem to be absolutely essential to the Austrian continued possession of Gorizia. It is scarcely a mile and a half away and absolutely dominates Gorizia and the hills in its rear in every way. The northern top of the plain on which Gorizia is situated, while considerably more distant from Podgora than is the city proper, is still within comparatively short range for heavy artillery and is moreover controlled from the heights of Oslavia north of Podgora on the same side of the river. Podgora has therefore been one of the points which have borne the brunt of ex tremely heavy attacks and is reported, together with Oslavia, to have fallen into Italian hands. If this proves to be true, the fall of Gorizia is much nearer than Another point of interest in the fighting along the lower Isonzo is the battle for the Dobrado plateau, some three miles southeast of Gradisca. The Austrians here are well entrenched and have offered a most effective resistance to the Italian advance. The Italians have howeve are slowly pushing the Austrians back. This will be somewhat facilitated now by the capture a few days ago of the heights of San Michele and San Martino de Corso to the northwest of the plateau, both of which are considerably higher than any other points in the vicinity. The fighting on the plateau itself has been trench warfare pure and simple, entirely analogous to the fighting in France. The advance has been extremel slow, is measured in fact in yards. Once Gorizia falls, the way to Trieste is clear. The country between the Isonzo and the railroad entering Trieste from the north is for the most part open and there is not a single fortified place between. From Gorizia there is a railroad tween. From Gorizia there is a railroad
line straight to Trieste which will mark the line of the Italian advance. The Italians, with the bridge head over the river in their hands, will be able to clear all of the west bank of the river of Austrians and will then control this bank from Plava to the river mouth. Pivoting there either on Playa or Tolmein, their superiority in numbers will enable them to push across the open country to the south and bring again under Italian rule their citizens who for years have bee looking forward to the day when they should again be living under the flag of King Humbert.

Electric Heating and Cooking Concluded from page 496)

Valuable Books of Instruction and Referenc

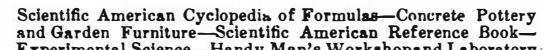
MUNN \& CO., Inc., Publishers, Woolworth Bldg., New York

LET 'TECLA' DEVELOP IT! Electrical and mechanical devices developed and built by experts. ted. Patent Office models. Special machinery and fine instruments designed and constructed. Experimental work, especially railroad
signalling, and Radio. Also autosignalling, and Radio. Also autoTECLA ELECTRICAL LABORATORY any other scientific or techthical books published, and for
ward them by mail or receipt of the reg lar advertised price.
res TS Send s your name and addrese and a copy of thio
catalogue will be mailed to you free of charge.

MUNN \& CO., Inc., Publishers American Office, 233 Brondway, New Yor
Consulting Electrical and Consulting Electrical and DETROIT, MICH.

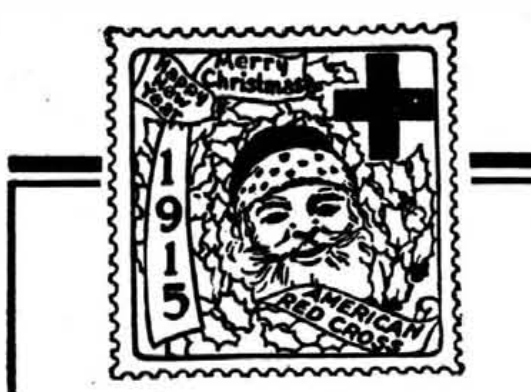

Right in Your Own Town YOUR Christmas Gift Might HELP

Get YOUR share of Christ mas Happiness by helping those who are fighting

Tuberculosis in your country and right in your own state or town.

Every effort you make to destroy Tuberculosis, will save life, add to the wealth of the community, and lessen the tax required for the support of institutions aiding tuberculous patients and those dependent upon them. Help stamp out the dread White Plague by buying Red Cross Christmas Seals. It is your fight-for Humanity's sake. Do your share for your community. Even one seal will RED CROSS Christmas Seals

If you cannot buy Red Cross Seals in
your town, write to AMERICAN RED CROSS. Washington, D. C., for as

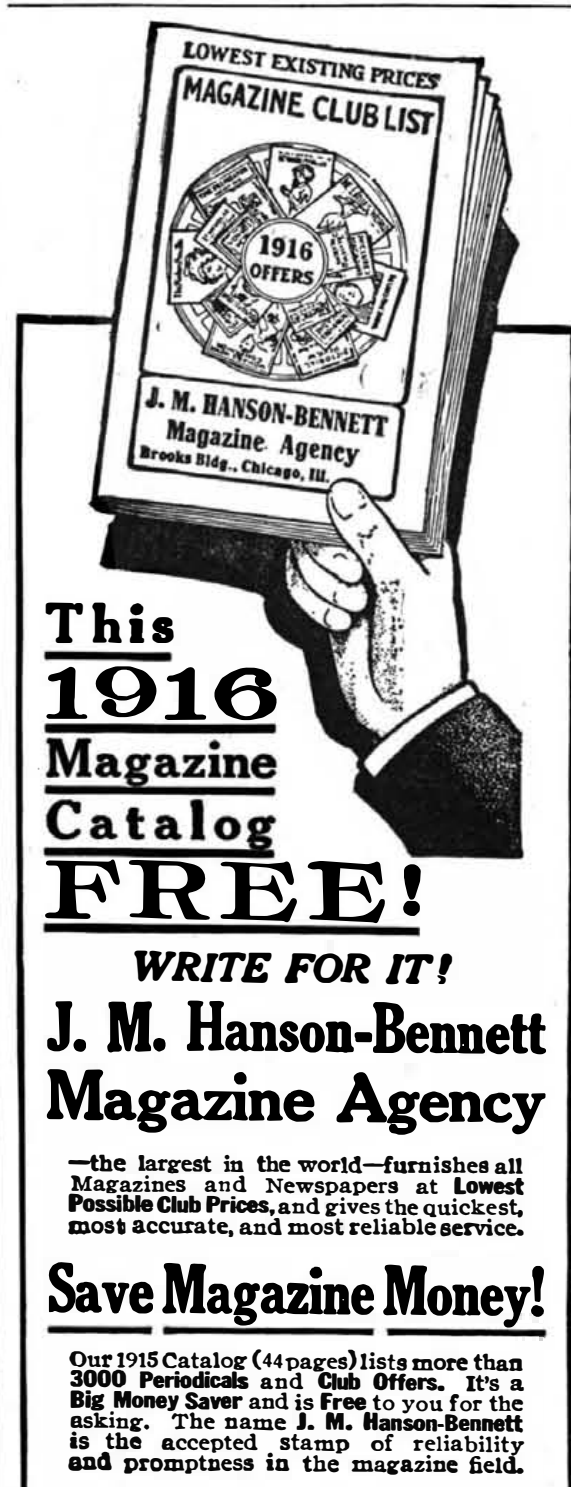

Local Agents Wanted Send U. YOUR TODAY! ADDRESS

J.M. HANSON-BENNETT

MAGAZINE AGENCY
846 Brooks Bullding CHICAGo, 1 LL. 


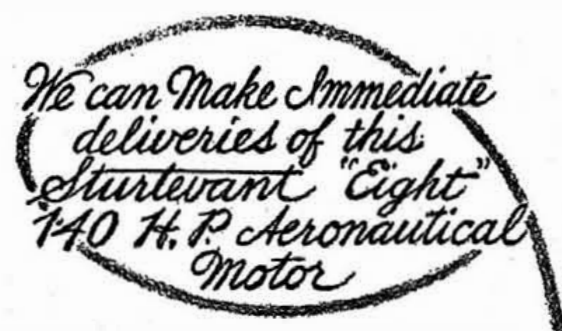

We have greatly increased our manufacturing facilities and can make immediate deliveries of these exceptional motors in quantities to suit purchaser.

The operation of the Sturtevant "Eight" in actual service has thoroughly proven its reliability and serviceability.

High Speed V type, propeller driven through reducing gear

High Volumetric Efficiency

Minimum Vibration

Two Magnetos

Weight four lbs. per Horse-$$
\text { power. }
$$

Built by the largest company manufacturing Aeronautical Motors in the U.S.

Full information and specifications sent to prospective clistomers.

\section{B. F. STURTEVANT CO.}

Hyde Park, Boston, Mass.

and all principal cities of the world
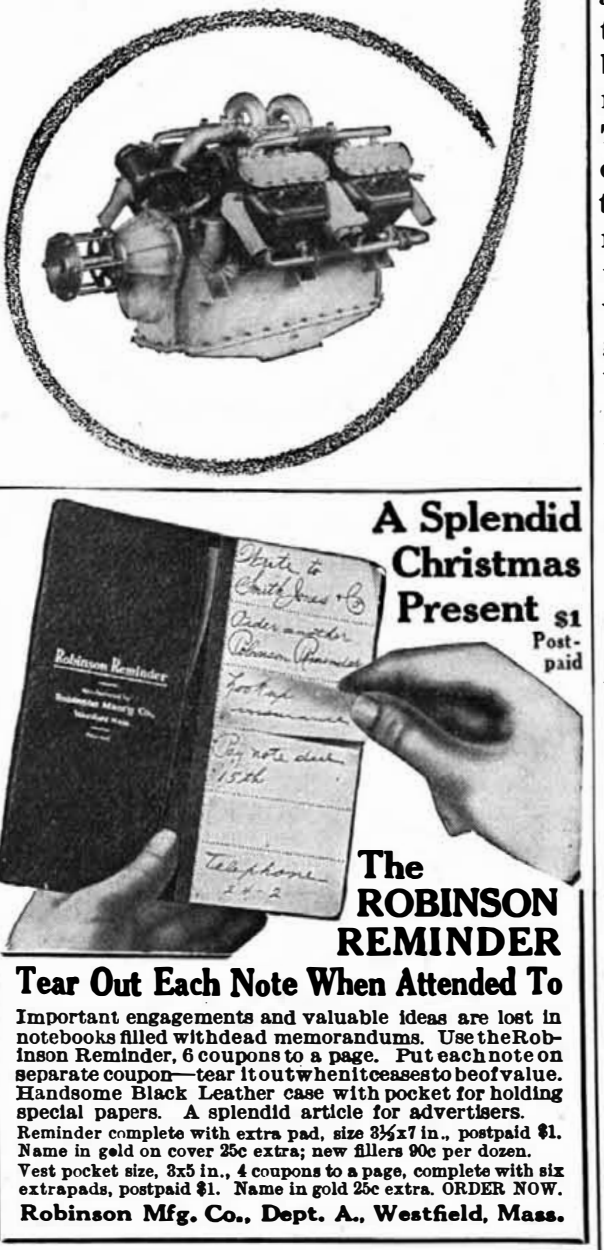

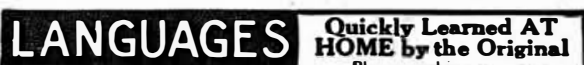

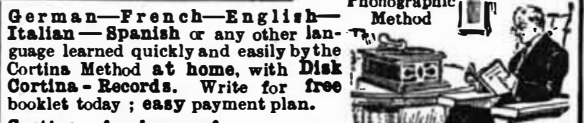

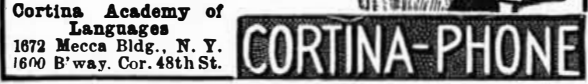
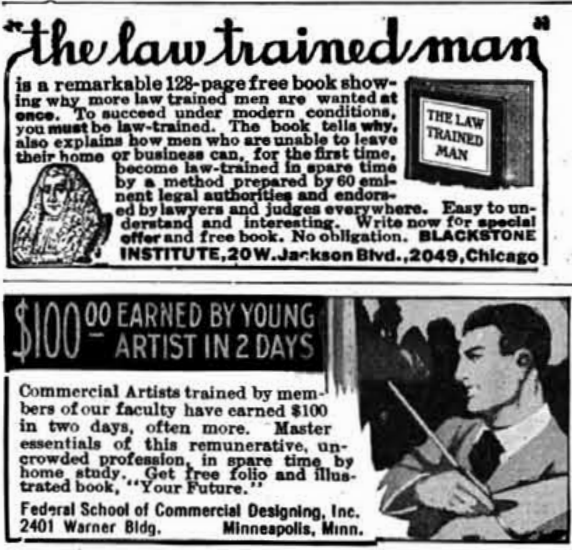

in a well insulated oven to keep the food hot after the current is turned off.

In cookery as in photography the time and temperature methods will benefit the amateur to a greater extent than the professional, who because of his years of experience and many failures in learning whil be able to get uniformly good results greatest field for an automatic electric oven will probably be in the middle class home where the cooking is done by the

housewife rather than by servants.

The Future of Radio Telephony (ample, as for instance in direct operation between two single wire less telegraph stations, this erratic variadrance to an economical and wide use of radio telephony as a link in a complicated telephone system covering a continent. Unfortunately for the radio enginee the electrical impulses purposely radiated from the sending antenna are not the wards through space. The more troublesome of these are due to natural causes originating wherever adjustments in electrical equilibrium are taking place, as in the case of lightning discharges, and "static" or, as they have been termed by some wireless workers, "X's." Another difficulty of a somewhat similar nature is that wireless receiving stations are sus ceptible to induction from near-by power especially that whose use involves rapid electric surges. With the present limited use of wireless, this latter trouble can be avoided by carefully choosing the location of receiving stations, but it would radio telephony became at all genera The interruptions due to static are, however, so serious that, at the present time, methods from superseding wire working, where such can be maintained. While very probably methods somewhat mitigating the effects of static may be developed in the future, no economical and the present time.

Inherently wireless telephony is nonsecret for the reason that in wireless working all interested make a common ether. No matter how complicated or un usual the apparatus and system employed by one group, the instant another person ilar type of receiving set the element of secrecy vanishes. Under any conceivable conditions this factor of non-secrec stitute for a wire plant.

Even more fundamental in the nature of things is the fact that, while radio telegraphy requires the transmission through space of electrical oscillations of telephony on the other hand requires for telephony on the other hand requires for group of frequencies depending upon the range of pitch of the human voice. To illustrate, assume it is desired to imploy for wireless signaling a fundamental or length corresponding to oscillations of frequency of 60,000 periods per second. In the case of telegraphy this frequency
only is sent out and it is theoretically possible to tur and it is theoretically quency as to enable another sending to be made at a frequency extremely near to this. In fact the degree- of closeness is only limited by the refinement and commissible. On the other hand, in the case of radio telephony the limitation referred to above enters, so that when a current or 60,000 periods per second, sulting from such modulation cover range in frequency of several thousan periods per second. If, therefore, it is desired to avoid overhearing and confusio of sounds it is necessary, even with idea ly perfect apparatus, to employ fundamental frequencies as far apart as several

\section{What Should an EngineWeigh?}

When asked how long a man's legs should be, Abraham
Lincoln decided they should be long enough to reach the Lincoln decided they should be long enough to reach the An engine should weigh enough to give it stability-
and no more. In these days of careful designing and advanced light-
weight construction, it is no longer necessary to hold an en efficiency - reduced friction and lowered operating cost.
Cushman Engines are the leading American light weight, hig efficiency, all-purpose motors, challenging comparison in minimum
weight per horsepower, reduced friction, quality of material an Cushman Light Weight Engines

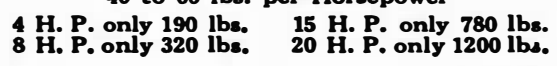

Cushman Engines are used for a greater range of work than
any other 4-cycle engine on the market. Besides doing all station- Equpped with Schebler Carburo-
ary wor and Frtetlon Clutch Pulley weight, they may also be attached to stationary
or movable machines, such as Grain Binders, Hay cures very steady speed, even on work of sudde Balers, Corn Pickers, Potato Diggers, Concrete variation in power requirements. Moving parts
Mixers and Hoists. Euiped with Schebler Car- enclosed and run in bath of oil. A vertical engine
buretor, Friction Clutch Pulley and Forced Water makes possible better oiling and balancing, result Cushman Engines_are not cheap englnes, but they are cheap in the long run

CUSHMAN MOTOR WORKS, 884 North 21 st St., LINCOLN, NEBRASKA
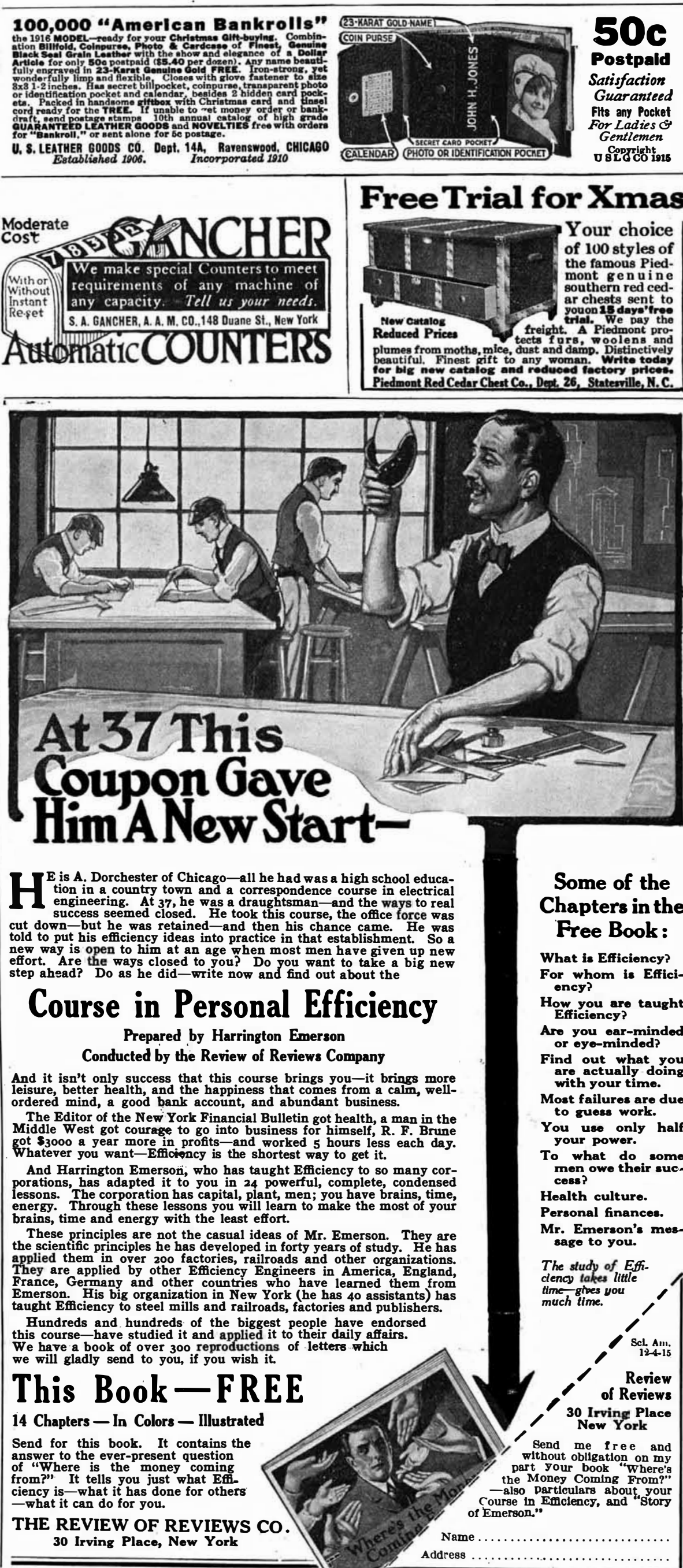